\title{
LACIS-measurements and parameterization of sea-salt particle hygroscopic growth and activation
}

\author{
D. Niedermeier, H. Wex, J. Voigtländer, F. Stratmann, E. Brüggemann, A. Kiselev, H. Henk, and J. Heintzenberg \\ Leibniz Institute for Tropospheric Research, Permoser Str. 15, 04318 Leipzig, Germany
}

Received: 17 July 2007 - Published in Atmos. Chem. Phys. Discuss.: 6 August 2007

Revised: 14 December 2007 - Accepted: 3 January 2008 - Published: 7 February 2008

\begin{abstract}
The Leipzig Aerosol Cloud Interaction Simulator (LACIS) was used to investigate the hygroscopic growth and activation of sea-salt particles which were generated from three different sea-water samples. The measurements showed that the sea-salt particles exhibit a slightly reduced hygroscopic growth compared to pure $\mathrm{NaCl}$ particles. Köhler theory was utilized to model the hygroscopic growth of these particles. Some parameters used in this model are unknown for sea-salt. These parameters are combined in an "ionic density" $\rho_{\text {ion }}$. For each sea-salt sample an average $\rho_{\text {ion }}$ was determined by fitting the Köhler equation to the data from the hygroscopic growth measurements. LACIS was also used to measure the activation of the sea-salt particles at three different supersaturations: $0.11 \%, 0.17 \%$ and $0.32 \%$. A CCNclosure was tested by calculating the critical diameters $D_{\text {crit }}$ for the sea-salt particles at these supersaturations, using the Köhler model and the corresponding $\rho_{\text {ion }}$ as derived from the hygroscopic growth data. These calculated critical diameters were compared to the measured ones. Measured and calculated values of $D_{\text {crit }}$ agree within the level of uncertainty. Based on this successful closure, a new parameterization to describe sea-salt-particle hygroscopic growth (at $\mathrm{RH}>95 \%$ ) and activation has been developed.
\end{abstract}

\section{Introduction}

Most of the earth's surface is covered by oceans. For that reason marine aerosol particles largely affect the global climate. Depending on their optical properties, marine aerosol particles scatter and absorb the incoming solar radiation and therefore influence the radiation budget of the earth (Fitzgerald, 1991). The optical properties of the particles depend

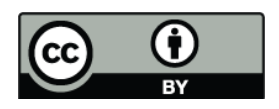

Correspondence to: D. Niedermeier (niederm@tropos.de) on the particle size distribution, their shape and their chemical composition and through their hygroscopicity also on the ambient relative humidity (Pilinis et al., 1995; Randles et al., 2004).

Due to their hygroscopicity the marine aerosol particles act as cloud condensation nuclei (CCN). They influence the cloud droplet size distribution and hence indirectly the radiation budget. The contribution of marine stratus and stratocumulus clouds to the earth's albedo is about $30 \%$ to $40 \%$ (Randall et al., 1984).

The marine aerosol principally consists of sea-salt, nonsea-salt (nss) sulfate particles and possibly biological particles from the ocean microlayer (Leck and Bigg, 2005a,b). Sea-salt particles are produced in a direct and an indirect way (Blanchard and Woodcock, 1957, 1980; Gong et al., 1997; O'Dowd et al., 1997). For wind speeds larger than $4 \mathrm{~m} \cdot \mathrm{s}^{-1}$ waves are generated due to wind stress. These waves break and thereby sea-salt droplets with diameters greater than $10 \mu \mathrm{m}$ are produced (Fitzgerald, 1991). During this wave breaking process also air bubbles are introduced into the surface water. They rise and burst after reaching the surface, producing so called film and jet drops. Depending on the bubble size, about ten jet drops with an average diameter of $1-2 \mu \mathrm{m}$ and several hundred film drops with a diameter smaller than $1 \mu \mathrm{m}$ are generated (O'Dowd et al., 1997). Since the relative humidity $(\mathrm{RH})$ over the ocean surface is about $98 \%$, the generated drops evaporate until the water vapor pressure over the drop surface is equal to that of the environment (Blanchard and Woodcock, 1980).

Nss-sulfate particles also play an important role in the marine atmosphere. The main source of these particles in the remote marine boundary layer is dimethylsulfide (DMS) which is mainly produced by phytoplankton (Andreae and Raemdonck, 1983; Andreae et al., 1985). Typical nss-sulfate particle concentrations in clean marine air lie within 50 to $100 \mathrm{~cm}^{-3}$ (O'Dowd et al., 1997). Although nss-sulfate particles are less hydrophilic than sea-salt particles, they play an

Published by Copernicus Publications on behalf of the European Geosciences Union. 
Table 1. Concentration and mass fraction of major ions for the three sea-water samples.

\begin{tabular}{|c|c|c|c|c|c|c|}
\hline \multirow[b]{2}{*}{ Ions } & \multicolumn{2}{|c|}{ Sample I } & \multicolumn{2}{|c|}{ Sample II } & \multicolumn{2}{|c|}{ Sample III } \\
\hline & $\begin{array}{r}C_{\mathrm{s}} \\
{\left[\mathrm{g} \cdot \mathrm{l}^{-1}\right]}\end{array}$ & $\begin{array}{r}\xi_{\mathrm{s}} \\
{[\%]}\end{array}$ & $\begin{array}{r}C_{\mathrm{s}} \\
{\left[\mathrm{g} \cdot 1^{-1}\right]}\end{array}$ & $\begin{array}{r}\xi_{\mathrm{s}} \\
{[\%]}\end{array}$ & $\begin{array}{r}C_{\mathrm{S}} \\
{\left[\mathrm{g} \cdot \mathrm{l}^{-1}\right]}\end{array}$ & $\begin{array}{r}\xi_{\mathrm{s}} \\
{[\%]}\end{array}$ \\
\hline $\mathrm{Cl}^{-}$ & 4.22 & 51.75 & 3.87 & 53.94 & 19.37 & 61.06 \\
\hline $\mathrm{NO}_{3}^{-}$ & 0.02 & 0.25 & 0.04 & 0.56 & 0.05 & 0.14 \\
\hline $\mathrm{SO}_{4}^{2-}$ & 0.75 & 9.17 & 0.56 & 7.85 & 2.82 & 8.89 \\
\hline $\mathrm{Na}^{4}$ & 2.60 & 31.89 & 2.18 & 30.39 & 7.66 & 24.15 \\
\hline $\mathrm{K}^{+}$ & 0.13 & 1.59 & 0.09 & 0.09 & 0.36 & 1.12 \\
\hline $\mathrm{Mg}^{2+}$ & 0.25 & 3.04 & 0.29 & 3.97 & 1.08 & 3.41 \\
\hline $\mathrm{Ca}^{2+}$ & 0.19 & 2.31 & 0.15 & 2.06 & 0.39 & 0.39 \\
\hline
\end{tabular}

important role in cloud formation processes. Measurements have shown that for small wind speeds the concentration of nss-sulfate particles in the accumulation mode, i.e., in the mode which provides most of the $\mathrm{CCN}$, is larger than that of the sea-salt particles. As sea-salt particles mainly occur in the coarse-mode, it was expected that these particles contribute a negligible amount to the $\mathrm{CCN}$ in comparison to nss-sulfate particles (Charlson et al., 1987), because larger particles are removed from the atmosphere more quickly than smaller ones. Observations of O'Dowd and Smith (1993), however, showed that under adequate wind conditions the sea-salt particles also occur in the accumulation mode down to sizes of $100 \mathrm{~nm}$. They can even dominate this size range, because the wave activity increases with increasing wind speed. More air bubbles are produced and thus more film and jet drops are generated. Over a period of low wind speeds the number concentration of sea-salt particles ranges between 5 and $30 \mathrm{~cm}^{-3}$ (Blanchard and Cipriano, 1987). With an increase of wind speed to $17 \mathrm{~m} \cdot \mathrm{s}^{-1}$ the concentration in the accumulation mode may exceed $70 \mathrm{~cm}^{-3}$ (O'Dowd et al., 1997). Due to updrafts, sea-salt particles are transported up to the cloud base and consequently even under moderate meteorological conditions more than $90 \%$ of the activated $\mathrm{CCN}$ in marine stratocumulus clouds may consist of sea-salt (O'Dowd et al., 1997).

As mentioned above, marine aerosol particles mainly consist of hygroscopic particles. Thereby the scattering of the incoming solar radiation depends on the ambient relative humidity, because the amount of the scattered light is related to the particle size. The particle diameters change with relative humidity, depending on the hygroscopic properties of the particles. To include the influences of sea-salt particles on scattering and cloud formation into numerical models, measurements of hygroscopic growth and activation are required. In this context it is also relevant to know, whether or not possible differences in the chemical composition of the oceans influence the hygroscopic growth and activation be- havior of the generated sea-salt particles. To explore the affect sea water chemical composition may have, sea-salt particles from three different sea-water samples were investigated regarding their hygroscopic growth and activation to cloud droplets. For the investigations the Leipzig Aerosol Cloud Interaction Simulator (LACIS, Stratmann et al. (2004)) was used. LACIS is a laminar flow tube that can operate at a stable $\mathrm{RH}$, which can be adjusted from almost $0 \%$ up to larger than $99 \%$ (Wex et al., 2005). It can also be used at supersaturations from $0.1 \%$ up to several percent.

For this study the hygroscopic growth of the different seasalt particles was measured in a $\mathrm{RH}$ range from $80.0 \%$ up to $99.1 \%$ (For the first time, measurements were performed at this high RH on sea-salt particles). It was investigated whether differences in the chemical composition cause differences in the hygroscopic behavior. Furthermore, the measured grown diameters were compared to the growth of pure sodium chloride particles. Dry $\mathrm{NaCl}$ particles possess a cubical shape. Since the main component of the three different sea-salt samples is $\mathrm{NaCl}$, it was investigated if a shape factor has to be taken into account for the generated sea-salt particles.

For the activation measurements of the sea-salt particles, supersaturations similar to those observed at the base of marine stratocumulus clouds $(0.1 \%$ to $0.3 \%$, Hudson and Frisbie, 1991) were used. Critical particle diameters were determined for the three different sea-salt samples and for pure $\mathrm{NaCl}$.

In addition, a CCN-closure was tested for different sea-salt particles and for $\mathrm{NaCl}$. For that purpose, the measured hygroscopic growth was used with Köhler theory to determine the critical particle diameters for activation with a method similar to that introduced in Wex et al. (2007).

Based on this closure, a new parameterization to consistently describe sea-salt-particle hygroscopic growth (at $\mathrm{RH}>95 \%)$ and activation was developed.

\section{Chemical composition of the sea-water samples}

Three different sea-water samples were analyzed with respect to hygroscopic growth and activation. Two samples came from the Baltic Sea, sample I from the bay of Mecklenburg $\left(54^{\circ} 18.90^{\prime} \mathrm{N} ; 11^{\circ} 33.00^{\prime} \mathrm{E}\right)$ and sample II from east of Gotland $\left(57^{\circ} 19.20^{\prime} \mathrm{N} ; 20^{\circ} 03.00^{\prime} \mathrm{E}\right)$, both were collected in a depth of about $1-2 \mathrm{~m}$. Sample III was taken from the Atlantic Ocean (only the sample latitude of $45^{\circ} \mathrm{N}$ is known) in a depth of $3000 \mathrm{~m}$.

The three sea-water samples were analyzed concerning their inorganic chemical composition. For analysis of main ions, the samples were filtered and analyzed by ion chromatography (IC, Metrohm-Switzerland). A detailed description of this method is given by Brüggemann and Rolle (1998). The concentrations $\mathrm{C}_{\mathrm{s}}\left(\mathrm{g} \cdot \mathrm{l}^{-1}\right)$ and the mass fractions $\xi_{\mathrm{s}}(\%)$ of the detected ions are shown in Table 1. Be- 
sides these, more ions were found in the different samples in marginal concentrations (lower than the concentrations of the $\mathrm{NO}_{3}^{-}$-ions). The salinities of the Baltic sea samples were lower $\left(8.16 \mathrm{~g} \cdot \mathrm{l}^{-1}\right.$ for sample I and $7.18 \mathrm{~g} \cdot \mathrm{l}^{-1}$ for sample II) than the salinity of the Atlantic sample $\left(31.73 \mathrm{~g} \cdot \mathrm{l}^{-1}\right) . \mathrm{Cl}^{-}$ and $\mathrm{Na}^{+}$are the major ions for all samples. Regarding the mass fractions, the Atlantic sample and the two Baltic Sea samples differ in these two main ions only. While the fraction of the $\mathrm{Cl}^{-}$ions in the Atlantic sample is higher compared to the two Baltic Sea samples, the fraction of the $\mathrm{Na}^{+}$ions is lower compared to both Baltic Sea samples.

Based on the knowledge of the mass fractions and the molecular weights of the ions, the numbers of moles of the ions are computed first. Using these values, for each seawater sample the analyzed ions are combined to salts, which can be found in sea-salt particles: $\mathrm{NaCl}, \mathrm{MgCl}_{2}, \mathrm{MgSO}_{4}$, $\mathrm{Na}_{2} \mathrm{SO}_{4}, \mathrm{CaCl}_{2}$ and $\mathrm{KNO}_{3}$. For each sample, the amount of cations is not identical to the amount of anions. But the analysis of the $\mathrm{pH}$ value showed that each sea-water sample is nearly neutral. Therefore no compensation with $\mathrm{H}^{+}$ and $\mathrm{OH}^{-}$ions had to be taken into account. Hence, the salts were combined such that only the minimal part $(2.1 \%, 1.4 \%$ and $2.5 \%$ of the total mass of the sea-salt samples I, II and III) of ions remained.

The mass concentrations and the mass fractions of these salts are shown in Table 2 for each sea-water sample. With this knowledge and the mass fraction mixing rule the mean density $\rho_{\mathrm{s}}$ and mean molecular weight $M_{\mathrm{s}}$ were calculated of the particles which were generated from these sea-water samples:

$$
\begin{array}{lll}
\text { Sample I } & \rho_{\mathrm{s}}=2245.9 \mathrm{~kg} \cdot \mathrm{m}^{-3} & M_{\mathrm{s}}=67.7 \mathrm{~g} \cdot \mathrm{mol}^{-1} \\
\text { Sample II } & \rho_{\mathrm{s}}=2248.7 \mathrm{~kg} \cdot \mathrm{m}^{-3} & M_{\mathrm{s}}=68.4 \mathrm{~g} \cdot \mathrm{mol}^{-1} \\
\text { Sample III } & \rho_{\mathrm{s}}=2238.4 \mathrm{~kg} \cdot \mathrm{m}^{-3} & M_{\mathrm{s}}=67.6 \mathrm{~g} \cdot \mathrm{mol}^{-1}
\end{array}
$$

These values have to be considered as an approximation because of the assumptions that were used in their derivation. But the influence of $\mathrm{NaCl}$ in the sea-water samples can already be seen.

\section{Experimental setup}

Figure 1 shows the experimental setup. The sea-salt particles were generated from the three sea-water samples by using an atomizer (TSI 3075, TSI Inc., St. Paul, Minnesota, USA). $\mathrm{NaCl}$-particles were used as a reference throughout the whole work. All particles were generated by atomizing aqueous solutions of $2 \mathrm{~g}$ salt per liter of double de-ionized water. The sea-water samples were diluted accordingly.

The resulting aerosol particles were dried in a diffusion dryer to a relative humidity lower than $10 \%$. As stated in literature (Cziczo et al., 1997; Cziczo and Abbatt, 2000; Weis and Ewing, 1999) this RH could be too high to completely
Table 2. Concentration and mass fraction of the possible salts for the three sea-water samples.

\begin{tabular}{lrrrrrr}
\hline & \multicolumn{2}{c}{ Sample I } & \multicolumn{2}{c}{ Sample II } & \multicolumn{2}{c}{ Sample III } \\
Salt & $\begin{array}{c}C_{\mathrm{S}} \\
{\left[\mathrm{g} \cdot 1^{-1}\right]}\end{array}$ & $\xi_{\mathrm{s}}$ & \multicolumn{2}{c}{$C_{\mathrm{S}}$} & $\xi_{\mathrm{s}}$ & \multicolumn{2}{c}{$C_{\mathrm{S}}$} & $\xi_{\mathrm{s}}$ \\
& {$\left[\mathrm{g} \cdot 1^{-1}\right]$} & {$[\%]$} & {$\left[\mathrm{g} \cdot 1^{-1}\right]$} & {$[\%]$} \\
\hline $\mathrm{NaCl}$ & 5.88 & 73.56 & 4.95 & 69.99 & 18.28 & 70.74 \\
$\mathrm{MgCl}_{2}$ & 0.63 & 7.83 & 0.96 & 13.51 & 4.23 & 16.38 \\
$\mathrm{Na}_{2} \mathrm{SO}_{4}$ & 0.89 & 11.18 & 0.72 & 10.16 & 1.45 & 5.60 \\
$\mathrm{CaCl}_{2}$ & 0.30 & 3.74 & 0.24 & 3.44 & 1.08 & 4.18 \\
$\mathrm{KNO}_{3}$ & 0.03 & 0.41 & 0.07 & 0.92 & 0.07 & 0.28 \\
$\mathrm{~K}_{2} \mathrm{SO}_{4}$ & 0.26 & 3.28 & 0.14 & 1.98 & 0.73 & 2.82 \\
\hline
\end{tabular}

dry salt particles. However, as on the one hand, water remaining in the particles would result in an erroneous determination of the soluble mass, and on the other hand, differences between the measured and calculated grown diameters are small, one may conclude that the amount of water left after drying, does not significantly influence the measurement results.

A DMA (Differential Mobility Analyzer, Knutson and Whitby (1975), type "Vienna medium") was used to select a narrow dry particle size fraction. For hygroscopic growth measurements the investigated mobility diameters of the selected dry particles were 150 and $200 \mathrm{~nm}$ for the three seasalt samples and $\mathrm{NaCl}$. During the activation measurements, the dry mobility diameters were varied for fixed supersaturations.

The non-spherical shape of $\mathrm{NaCl}$ particles had to be accounted for by using a shape factor. Earlier measurements with LACIS (Wex et al., 2005) showed that for $\mathrm{NaCl}$ particles in the investigated size range a shape fator of 1.08 can be used (as stated in literature: Kelly and McMurry, 1992). As $\mathrm{NaCl}$ is the main component of the sea-salt particles, it could not be excluded that sea-salt particles require a shape factor for their description, too. Investigations with a system consisting of a DMA and an ELPI (Electric Low Pressure Impactor, Fernández de la Mora et al., 1990) showed that the $\mathrm{NaCl}$ particles and the particles from the three different sea-salt samples possess the same aerodynamic behavior (see Appendix A). Therefore for the investigations a shape factor of 1.08 was used for all sea-salt particles. From this it follows that the mass equivalent diameters of the selected particles were $139 \mathrm{~nm}$ and $185 \mathrm{~nm}$ for the hygroscopic growth measurements.

The number concentrations of the selected particles were determined with a CPC (TSI 3010, TSI Inc., St. Paul, Minnesota, USA), and were kept at $300-500 \mathrm{~cm}^{-3}$ with a dilution system upstream of the DMA. All flows were controlled with mass flow controllers (MKS 1179, MKS Instruments Deutschland GmbH, München, Germany) and were 


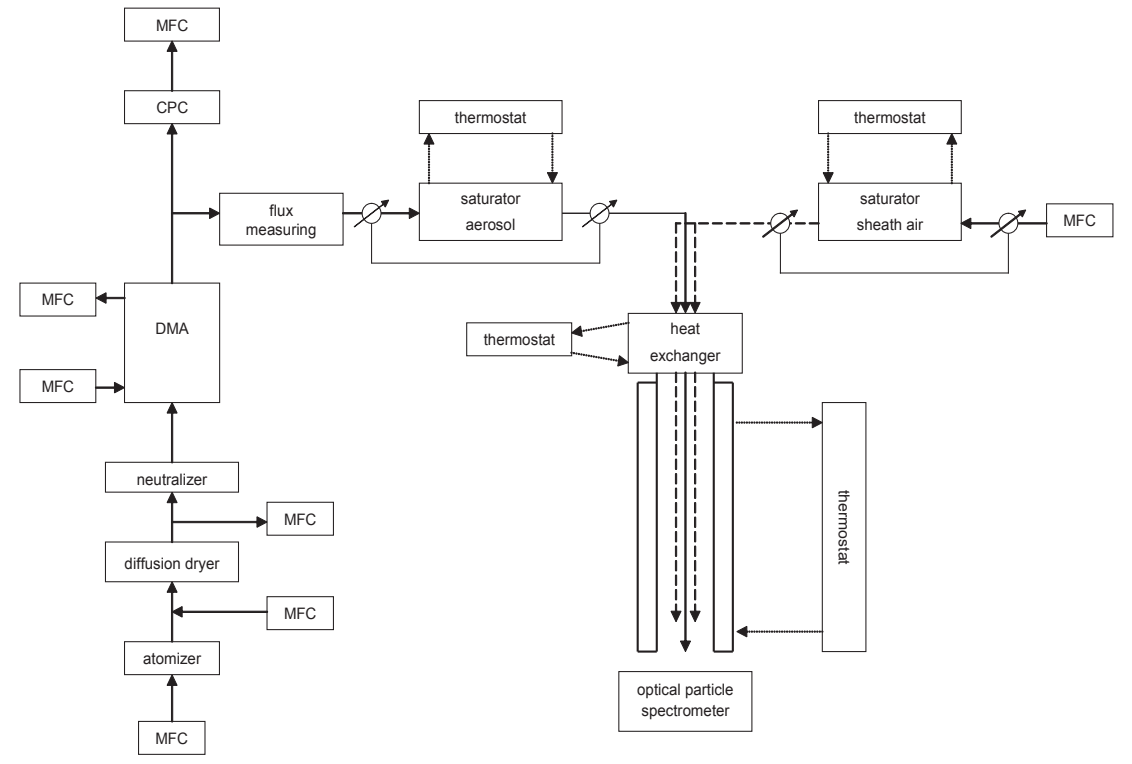

Fig. 1. Set-up of the particle generation and the LACIS flow tube.

checked on a daily basis with a bubble flow meter (Gilian ${ }^{\circledR}$ Gilibrator $^{\mathrm{TM}_{2}}$, Sensidyne Inc., Clearwater, Florida, USA).

Before entering LACIS, the aerosol passed through a saturator (Perma Pure MH-110-12S-4, Perma Pure LLC, Toms River, New Jersey, USA). The saturator consisted of a tube made of Nafion ${ }^{\circledR}$ which was surrounded by temperaturecontrolled water. The temperature of the water-jacket was kept at a defined value by circulating the water through a thermostat (HAAKE C25P, HAAKE GmbH, Karlsruhe, Germany). The temperature of the thermostat was regulated by the signal of a Pt-100 resistance thermometer that measured the temperature of the water at the aerosol outlet of the saturator. Therewith, the saturator was used in a counter flow fashion. Downstream of the saturator, the dew point temperature of the aerosol was equal to the temperature at the saturator outlet. This was verified with a dew point mirror (Dew Prime I-S2, Edge Tech, Milford, Massachusetts, USA), which measures with an accuracy of $0.1 \mathrm{~K}$. A similar setup was used to humidify particle-free sheath air. Humidified aerosol and sheath air, both with the same dew point temperatures, were combined in the LACIS head. The aerosol was confined by the sheath air in a narrow beam (about $2 \mathrm{~mm}$ in diameter) at the center axis of LACIS.

LACIS itself is a laminar flow tube with a diameter of $15 \mathrm{~mm}$ and a length of $1 \mathrm{~m}$, surrounded by a thermostated water-jacket (thermostat: HAAKE C40P, HAAKE GmbH, Karlsruhe, Germany). The difference between the dew point temperature of the aerosol and sheath air flow and the temperature of the LACIS water-jacket determines the $\mathrm{RH}$ inside LACIS. For studying the hygroscopic growth of the different salt particles, LACIS was kept at a constant temperature of $20.0^{\circ} \mathrm{C}$. The saturator temperatures were varied from $16.5^{\circ} \mathrm{C}$ to $19.9^{\circ} \mathrm{C}$, resulting in relative humidities $(\mathrm{RH})$ from $80.0 \%$ to $99.1 \%$. Inside the flow tube, the $\mathrm{RH}$ reaches a constant value at approximately $20 \mathrm{~cm}$ downstream of the inlet. When measuring particle activation, the saturator temperature was kept at a constant temperature of $22.0^{\circ} \mathrm{C}$. The temperature of the LACIS water-jacket was set to different temperatures: $5.65^{\circ} \mathrm{C}, 5.45^{\circ} \mathrm{C}$ and $5.3^{\circ} \mathrm{C}$. This is equivalent to supersaturations of $0.11 \%, 0.17 \%$ and $0.32 \%$.

The residence time of the aerosol inside LACIS is about $2 \mathrm{~s}$. At the outlet of the flow tube the size of the grown particles/droplets is measured with an optical particle counter (OPC) that was designed and built especially for LACIS. For a detailed description see Kiselev et al. (2005). The optical particle sizer was calibrated with PSL particles with diameters of $299 \mathrm{~nm}, 404 \mathrm{~nm}, 499 \mathrm{~nm}, 701 \mathrm{~nm}, 799 \mathrm{~nm}$ and $1444 \mathrm{~nm}$. For the determination of the response function of the OPC, the refractive index of the humidified particles, which varies as a particle grows, was estimated using a volume mixing rule (e.g., Seinfeld and Pandis, 1998).

\section{Theory}

In the following, two different theoretical approaches will be described: first, the modeling of hygroscopic growth based on the Pitzer model (Pitzer and Mayorga, 1973), and second, 
a method that allowed to model the activation behavior based on the measured hygroscopic growth.

For the simulation of the measured hygroscopic growth, simple Köhler theory, including the Kelvin- and the Raoultterm, was applied. Generally, the Köhler equation can be written as (Pruppacher and Klett, 1997):

$S=a_{\mathrm{w}} \cdot \exp \left(\frac{4 M_{\mathrm{w}} \sigma_{\mathrm{sol}}}{R T \rho_{\mathrm{w}} D_{\mathrm{wet}}}\right)$

where $M_{\mathrm{w}}$ is the molecular weight of water, $\sigma_{\mathrm{sol}}$ is the droplet surface tension, $R$ is the gas constant, $T$ is the temperature, $\rho_{\mathrm{w}}$ is the density of water, $D_{\text {wet }}$ is the droplet diameter and $a_{\mathrm{w}}$ is the water activity.

In this study, the surface tension of water $\sigma_{\mathrm{w}}$ is used in the Kelvin-term of the Köhler equation.

The water activity, which represents the Raoult term, $a_{\mathrm{w}}=\gamma_{\mathrm{w}} \cdot x_{\mathrm{w}}$ in Eq. (1) is the product of water activity coefficient and water mole fraction. For this study, the water activity coefficient was calculated applying the Pitzer model (Pitzer and Mayorga, 1973). In the model, full dissociation of the salts in the particles was assumed. For the sea-salt particles only the ions, found in the sea-salt samples (see Table 1), were used.

For the second approach, i.e. the modeling of the activation based on the measured hygroscopic growth, a different formulation of $a_{\mathrm{w}}$ in the Köhler equation was used:

$S=\exp \left(\frac{4 M_{\mathrm{w}} \sigma_{\mathrm{w}}}{R T \rho_{\mathrm{w}} D_{\text {wet }}}-\frac{v \phi_{\mathrm{s}} \rho_{\mathrm{s}}}{M_{\mathrm{s}}} \frac{M_{\mathrm{w}}}{\rho_{\mathrm{w}}} \frac{D_{\mathrm{me}_{0}}^{3}}{D_{\mathrm{wet}^{3}}^{3}-D_{\mathrm{me}_{0}}^{3}}\right)$

with the density of the solute $\rho_{\mathrm{s}}$, the molecular weight of the solute $M_{\mathrm{s}}$, the osmotic coefficient $\phi_{\mathrm{s}}$ (accounting for the non-ideality of the solution), the number of ions $v$ per solute molecule and the dry mass-equivalent diameter $D_{\mathrm{me}_{0}}$.

In the Raoult-term of Eq. (2), neither $\phi_{\mathrm{s}}$ nor $v$ are known, and for $\rho_{\mathrm{S}}$ and $M_{\mathrm{S}}$ only the approximations derived in Sect. 2 exist for the different sea-salt samples. Therefore these parameters were combined into a so called "ionic density" $\rho_{\text {ion }}$ (unit: $\mathrm{mol} \cdot \mathrm{m}^{-3}$ ) (Wex et al., 2007):

$\rho_{\text {ion }}=\frac{\nu \phi_{\mathrm{s}} \rho_{\mathrm{s}}}{M_{\mathrm{s}}}$.

$\rho_{\text {ion }}$ was derived for each sea-salt sample using the measured hygroscopic growth and is later on used to determine critical diameters for the activation for the $\mathrm{CCN}$-closure, performed in this study.

\section{Measurements of hygroscopic growth and activation of the sea-salt particles}

\subsection{Hygroscopic growth}

The measurements were performed for RHs between $80.0 \%$ and $99.1 \%$. The used RH-range was calibrated with ammonium sulfate particles. The hygroscopic growth of

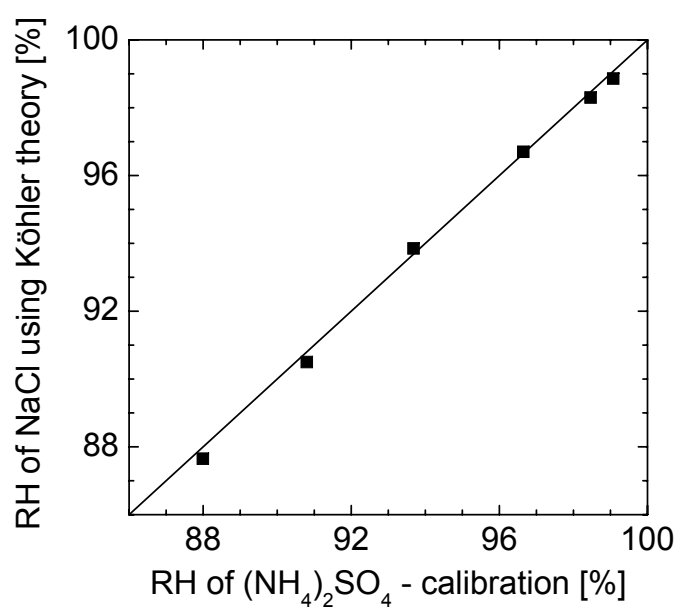

Fig. 2. RHs as determined from the hygroscopic growth of $\mathrm{NaCl}$ particles with $D_{\mathrm{me}_{0}}=185 \mathrm{~nm}$ are plotted versus RHs resulting from the calibration with ammonium sulfate particles with $D_{\mathrm{me}_{0}}=192 \mathrm{~nm}$.

$\left(\mathrm{NH}_{4}\right)_{2} \mathrm{SO}_{4}$ particles $\left(D_{\mathrm{me}_{0}}=192 \mathrm{~nm}\right)$ was measured for several adjusted dew point temperatures, i.e., relative humidities. Köhler theory, according to Eq. (1) with $\sigma_{\mathrm{w}}$ was applied to obtain the RH in LACIS from the grown particle diameters. Hence, each adjusted dew point is related to a defined value of $\mathrm{RH}$. The sea salt and $\mathrm{NaCl}$ investigations were performed at these RHs (dew points). In Fig. 2, RHs as determined from the hygroscopic growth of $\mathrm{NaCl}$ particles with a dry mass equivalent diameter $D_{\mathrm{me}_{0}}$ of $185 \mathrm{~nm}$ are plotted versus RHs resulting from the calibration with $\left(\mathrm{NH}_{4}\right)_{2} \mathrm{SO}_{4}$ particles with $D_{\mathrm{me}_{0}}=192 \mathrm{~nm}$. For both materials Köhler theory according to Eq. (1) with the surface tension of water was used. For RH $>86 \%$, the quality of the calibration becomes clear, as the maximum relative deviation amounts to $0.5 \%$. It should be noted that for $\left(\mathrm{NH}_{4}\right)_{2} \mathrm{SO}_{4}$ particles a shape factor $\chi$ of 1.04 was considered for calibration. This shape factor resulted from aerodynamic investigations equal to those done for the sea-salt and $\mathrm{NaCl}$ particles (see Appendix A). However, it should be mentioned that a comparison between the calibration using $\chi=1$ and $\chi=1.04$ for $\left(\mathrm{NH}_{4}\right)_{2} \mathrm{SO}_{4}$ particles showed that the shape factor only has a small influence on the derived $\mathrm{RH}$ at $\mathrm{RH}>86 \%$ (see Appendix $\mathrm{B}$ ).

For the hygroscopic growth investigations of the sea-salt and $\mathrm{NaCl}$ particles, mass-equivalent particle diameters of $139 \mathrm{~nm}$ and $185 \mathrm{~nm}$ were used. For each RH, each substance and each particle diameter at least three measurements were performed.

As an example Fig. 3 shows the hygroscopic growth of the sea-salt particles for sample III and $\mathrm{NaCl}$ particles for comparison. Plotted are wet diameters $D_{\text {wet }}$ as function of RH for the two dry diameters considered. In addition, theoretical 


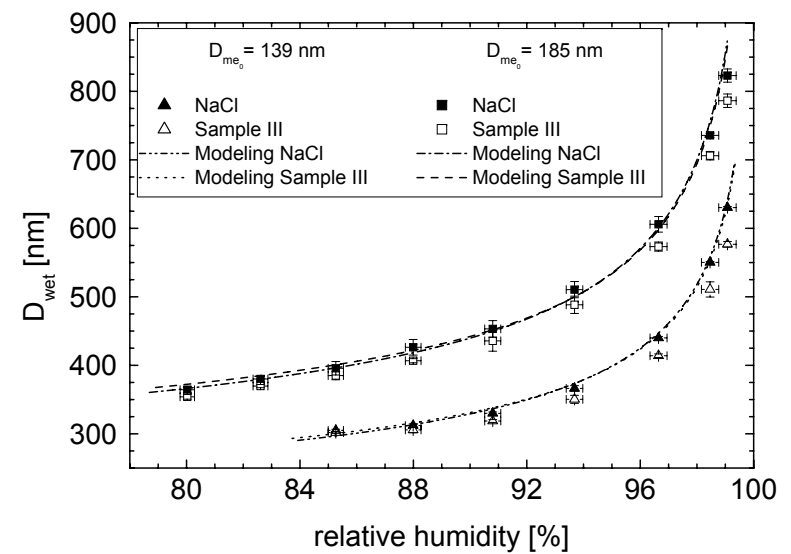

Fig. 3. Hygroscopic growth of the sea-salt particles of sample III at different values of $\mathrm{RH}$ compared to that of pure $\mathrm{NaCl}$. For comparison, theoretical curves for sea-salt sample III and $\mathrm{NaCl}$ are presented, too.

curves, calculated with Eq. (1), for the hygroscopic growth of these two substances are shown, too. The data points represent the mean values of at least three independent measurements. The error bars, being a measure for the experimental uncertainties, represent the maximum deviation from the mean values and the influences of fluctuations in $\mathrm{RH}$, respectively. Due to the lower detection limit of the OPC used to determine the size of the grown droplets, for salt particles with a dry diameter of $139 \mathrm{~nm}$ only RHs larger than $84 \%$ could be measured.

The measurements show (see Fig. 3), that especially at high RHs, the sea-salt particles exhibit a reduced growth compared to the $\mathrm{NaCl}$ particles. There is a good agreement between the measured and theoretical growth of the $\mathrm{NaCl}$ particles. The theoretically predicted growth of the sea-salt particles is slightly larger compared to the measured growth. However, this difference only amounts to $5 \%$ in the wet diameters at the highest measured RH. This small difference between the measurements and calculations may be caused by small amounts of additional less hygroscopic organic or insoluble substances in the sea-salt particles and uncertainties in the calculated density of the sea-salt particles.

The measured and calculated hygroscopic growth of the three sea-salt samples showed a similar behavior. In Fig. 4 the hygroscopic growth of the three samples is shown for a dry particle diameter of $185 \mathrm{~nm}$ in comparison to $\mathrm{NaCl}$ particles with the same dry size (The theoretical curves are not shown, because they nearly coincide for the sea-salt samples.). The measured grown sizes for particles generated from the three sea-water samples agree within the experimental uncertainties. This was also found for a dry diameter of $139 \mathrm{~nm}$. In other words, the hygroscopic growth of the three sea-salt samples was found to be very similar but

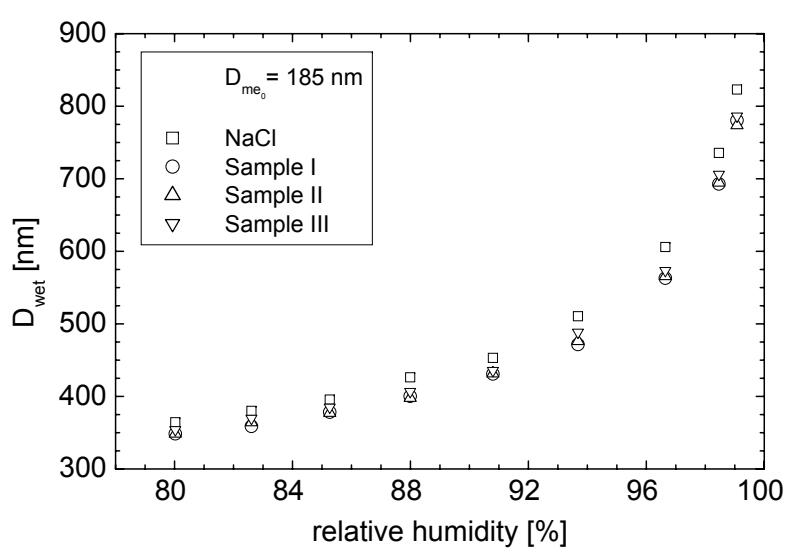

Fig. 4. Hygroscopic growth of sea-salt particles of the three different samples at different values of $\mathrm{RH}$ in comparison to pure $\mathrm{NaCl}$. For clarity, error bars are not shown.

always lower than that of pure $\mathrm{NaCl}$ particles. The theoretically predicted hygroscopic growth of all sea-salt samples was slightly larger than the measured growth.

\subsection{Activation}

Measurements were performed at supersaturations of $0.11 \%$, $0.17 \%$ and $0.32 \%$. The calibration of LACIS with respect to the supersaturation was done with ammonium sulfate particles (Wex et al., 2006). At each supersaturation the diameter of the investigated dry salt particles was varied until the critical diameter $D_{\text {crit }}$ was found. $D_{\text {crit }}$ is the diameter where the saturation in LACIS corresponded to the critical supersaturation which the particles needed to activate to cloud droplets. As for the investigations of hygroscopic growth, each activation measurement was repeated at least two times to gain a measure for the measurement uncertainties.

Figures 5 and 6 depict droplet diameters as measured for sea-salt (sample III) and $\mathrm{NaCl}$ particles, respectively as function of dry particle size. Values for the three different supersaturations are given. The data points represent mean values of at least two measurements which were performed on different days. The errors bars represent the maximum deviation from the mean values. The particles for which the supersaturation in LACIS is not sufficient for activation grow hygroscopically. They are in equilibrium with their environment. The larger particles for which the present saturation in LACIS is adequate for activation grow dynamically. Earlier activation measurements (Wex et al., 2006) showed that the results for hygroscopically grown particles could be linked through a straight line. The results for dynamically grown particles, however, could be reproduced by a polynomial curve. The intercept point of the polynomial curve and the straight line indicates $D_{\text {crit }}$. 


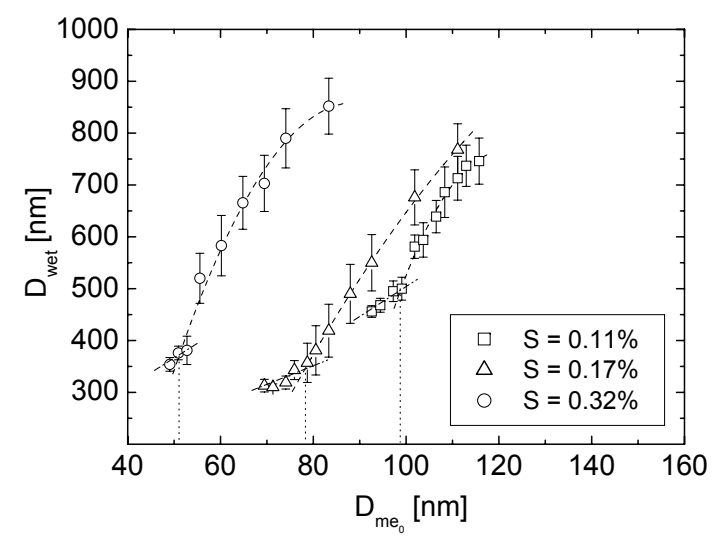

Fig. 5. Activation curves of the sea-salt particles of sample III at three different supersaturations. The intercept point of the polynomial curve and the straight line indicates $D_{\text {crit }}$.

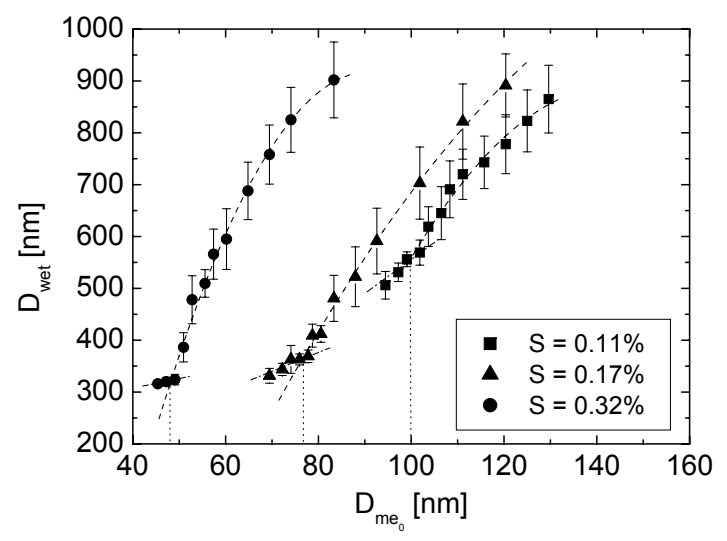

Fig. 6. Activation curves of the $\mathrm{NaCl}$ particles at three different supersaturations. The intercept point of the polynomial curve and the straight line indicates $D_{\text {crit }}$.

In Table 3, values of $D_{\text {crit }}$ are given for all sea-salt samples and for $\mathrm{NaCl}$. The given critical diameters correspond to the mean values of at least two measurements. The uncertainties represent the maximum deviation from the mean values found. It should be noted, that earlier calibrations regarding the supersaturations (and the corresponding uncertainties) inside LACIS yielded an uncertainty of approximately $\pm 0.03 \%$ in the supersaturation range used in this study.

At $0.11 \%$ supersaturation, the measured critical diameters for all sea-salt samples and for pure $\mathrm{NaCl}$ are identical within the measurement uncertainties. This is similar for the measurements at $0.17 \%$, where $D_{\text {crit }}$ of all sea-salt samples is slightly larger than that of $\mathrm{NaCl}$. At $0.32 \%, D_{\text {crit }}$ of the seasalt samples also is larger than that of $\mathrm{NaCl}$, even exceeding the measurement uncertainty for sample I.

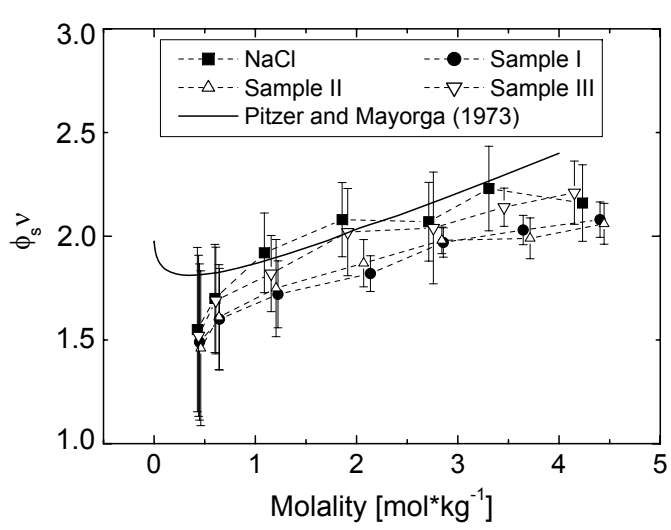

Fig. 7. $\phi_{\mathrm{s}} v$ derived from the measured hygroscopic growth for $\mathrm{NaCl}$ and the three sea-salt samples in comparison to values for $\mathrm{NaCl}$ as given in literature (Pitzer and Mayorga, 1973).

Table 3. Measured critical diameters and their experimental uncertainties for the three sea-salt samples and $\mathrm{NaCl}$.

\begin{tabular}{rrrrr}
\hline $\begin{array}{r}\text { S } \\
\%\end{array}$ & $\begin{array}{r}\text { Sample I } \\
{[\mathrm{nm}]}\end{array}$ & $\begin{array}{r}\text { Sample II } \\
{[\mathrm{nm}]}\end{array}$ & $\begin{array}{r}\text { Sample III } \\
{[\mathrm{nm}]}\end{array}$ & $\begin{array}{r}\mathrm{NaCl} \\
{[\mathrm{nm}]}\end{array}$ \\
\hline 0.10 & $105.0 \pm 5.0$ & $105.0 \pm 4.0$ & $99.0 \pm 5.0$ & $100.0 \pm 4.0$ \\
0.16 & $80.0 \pm 3.0$ & $77.0 \pm 3.0$ & $77.0 \pm 3.0$ & $76.5 \pm 3.0$ \\
0.30 & $55.0 \pm 2.0$ & $49.5 \pm 2.0$ & $51.0 \pm 2.0$ & $48.0 \pm 2.0$ \\
\hline
\end{tabular}

In summary, the activation behavior found for particles generated from the three sea-salt samples and from $\mathrm{NaCl}$ is nearly identical.

\section{CCN-closure}

The concept of $\rho_{\text {ion }}$ (Wex et al., 2007) was utilized to carry out a CCN closure test and to develop a parameterization for a consistent description of sea-salt particle hygroscopic growth and activation.

6.1 Obtaining $\rho_{\text {ion }}$ from the measured hygroscopic growth

Köhler theory based on Eq. (2) was used to simulate the measured hygroscopic growth of the different sea-salts and the $\mathrm{NaCl}$ particles. In the Köhler model, $\rho_{\text {ion }}$ was adjusted that the calculated wet diameters agreed with the measured values. This procedure was performed separately for each $\mathrm{RH}$ at which the measurements were performed.

The resulting values for $\rho_{\text {ion }}$ together with the derived values of the density and the molecular weight of the three seasalts can be used to derive the product of $\phi_{\mathrm{S}}$ and $v$.

In Fig. 7, this product is plotted versus the molality for the 


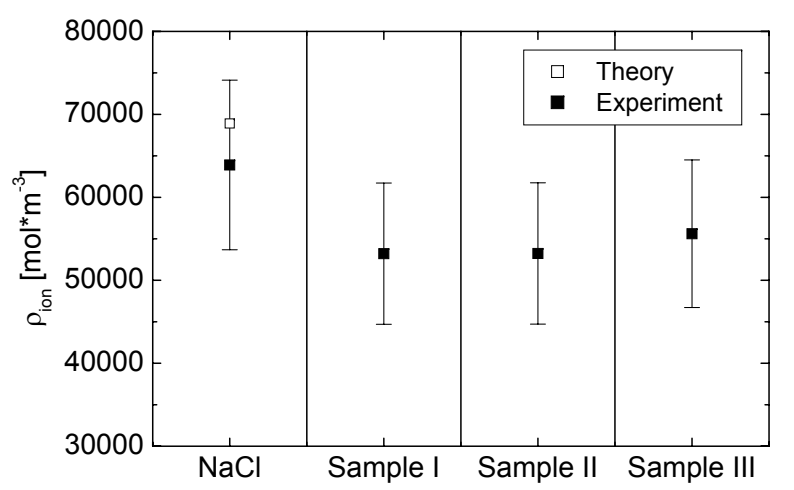

Fig. 8. The averaged values of $\rho_{\text {ion }}$ for $\mathrm{NaCl}$ and the three sea-salt samples. Additionally, the theoretical value for $\mathrm{NaCl}$ is shown.

three sea-salts and $\mathrm{NaCl}$, derived from $\rho_{\text {ion }}$, i.e. from the hygroscopic growth data, of particles with dry diameters of $185 \mathrm{~nm}$. The theoretical curve for $\mathrm{NaCl}$ (Pitzer and Mayorga, 1973 ) is shown in Fig. 7 as well. The corresponding molality $M$ is computed from:

$M=\frac{D_{\mathrm{me}_{0}}^{3}}{D_{\mathrm{wet}^{3}}^{3}-D_{\mathrm{me}_{0}}^{3}} \frac{\rho_{\mathrm{s}}}{M_{\mathrm{s}} \rho_{\mathrm{w}}}$

Fig. 7 shows that for $\mathrm{NaCl}, \phi_{\mathrm{s}} v$ derived from the hygroscopic growth and the theoretical curve agree within the range of uncertainty. The uncertainties in the values for $\phi_{\mathrm{s}} v$ originate from the uncertainty in the RH in the measurements of about $0.3 \%$ (absolute) and increase towards lower molalities. It is interesting to note that $\phi_{\mathrm{s}} v$ takes on comparable values and a comparable course for the three sea-salt samples and $\mathrm{NaCl} . \phi_{\mathrm{s}} v$ for Sample III agrees with that of $\mathrm{NaCl}$ within measurement uncertainty, while the values of $\phi_{\mathrm{s}} v$ for Sample I and II are slightly lower. However, with the data shown in Fig. 7, it can be said that the sea-salt samples show a similar trend in the non-ideal behavior than $\mathrm{NaCl}$.

\subsection{Comparison of the calculated and measured critical di- ameters}

For the calculation of the critical diameters, i.e., the diameters at which particles activate to become cloud droplets, only values of $\rho_{\text {ion }}$ for RHs above $95 \%$ were considered. This RH range, which corresponds to molalities smaller than $1.5 \mathrm{~mol} \cdot \mathrm{kg}^{-1}$, can be assumed to be a good approximation for the $\rho_{\text {ion }}$ at the point of activation. In Fig. 8, the average values for $\rho_{\text {ion }}$ in the RH range $>95 \%$ are shown for the three sea-salt samples and pure $\mathrm{NaCl}$.

A dilute solution of $\mathrm{NaCl}$ in water behaves nearly ideally $\left(\phi_{\mathrm{S}} \approx 0.93\right.$, averaged over an $\mathrm{RH}$ range from $95 \%$ to $99 \%$ and $\nu=2$ ), and the density and molecular weight of $\mathrm{NaCl}$ are

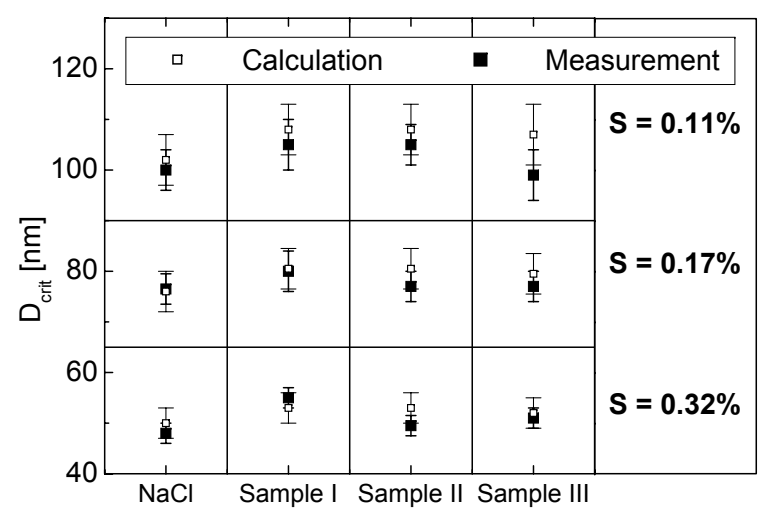

Fig. 9. Measured and calculated critical diameters for the three supersaturations.

known. Thus, a theoretical value for $\rho_{\text {ion }}$ can be calculated. This value is presented in Fig. 8, too (open square). It is obvious that this value lies well within the uncertainty of the experimentally determined $\rho_{\text {ion }}$. This underlines the high quality of the determined ionic densities and the feasibility and quality of the parameterization concept based on $\rho_{\text {ion }}$.

The derived values of $\rho_{\text {ion }}$ were used in the Köhler equation to calculate the critical diameters. The calculations were done for the three supersaturations: $0.11 \%, 0.17 \%$ and $0.32 \%$ considered during the experiments. In Fig. 9 the calculated and measured values of $D_{\text {crit }}$ are shown.

For the supersaturation of $0.11 \%$ the measured values of $D_{\text {crit }}$ of $\mathrm{NaCl}$, sample I, II and III are $2 \%, 2.8 \%, 2.8 \%$ and $7.1 \%$ smaller than the calculated ones. The measured and calculated critical diameters agree within the uncertainties. The measured and calculated critical particle diameters also coincide within the measuring accuracy at the supersaturation of $0.17 \%$ for all four substances. The measured value for $\mathrm{NaCl}$ is $0.7 \%$ higher than the calculated diameter. The measured diameters for sample I, II and III are 0.6\%, $4.3 \%$ and $3.1 \%$ smaller than the calculated value. At the supersaturation of $0.32 \%$, the measured values of $D_{\text {crit }}$ of $\mathrm{NaCl}$, sample II and III are $4.0 \%, 6.6 \%$ and $1.9 \%$ below the calculated ones. The measured value of sample I lies $3.8 \%$ above the measured diameter. Nevertheless, the measured and calculated values agree within the uncertainties.

In summary, using Köhler theory and $\rho_{\text {ion }}$ as determined from hygroscopic growth measurements, the critical diameters and consequently critical supersaturations at which particles activate to cloud droplets, were determined with good accuracy. The activation behavior of the three sea-saltsamples and $\mathrm{NaCl}$ was found to be nearly identical. 
Based on this, a new parameterization

$S=\exp \left(\frac{4 M_{\mathrm{w}} \sigma_{\mathrm{w}}}{R T \rho_{\mathrm{w}} D_{\mathrm{wet}}}-\rho_{\text {ion }} \frac{M_{\mathrm{w}}}{\rho_{\mathrm{w}}} \frac{D_{\mathrm{me}_{0}}^{3}}{D_{\mathrm{wet}^{3}}^{3}-D_{\mathrm{me}_{0}}^{3}}\right)$

respectively in linearized form (just given here for convenience)

$S=1+\frac{4 M_{\mathrm{w}} \sigma_{\mathrm{w}}}{R T \rho_{\mathrm{w}} D_{\mathrm{wet}}}-\rho_{\text {ion }} \frac{M_{\mathrm{w}}}{\rho_{\mathrm{w}}} \frac{D_{\mathrm{me}_{0}}^{3}}{D_{\mathrm{wet}^{3}}^{3}-D_{\mathrm{me}_{0}}^{3}}$

has been developed, to describe consistently sea-salt-particle hygroscopic growth (at $\mathrm{RH}>95 \%$ ) and activation. The parameterization is based on the concept of $\rho_{\text {ion }}$ (Wex et al., 2007) and the assumption of a surface tension equal to that of water $\left(\sigma_{\mathrm{w}}=72.8 \mathrm{mN} \cdot \mathrm{m}^{-1}\right)$ at activation. For seasalt, a mean value of $54000 \mathrm{~mol} \cdot \mathrm{m}^{-3}$ for $\rho_{\text {ion }}$ can be used. Entering these values of $\rho_{\text {ion }}, \sigma_{\mathrm{w}}$ and the other known parameters $\left(\rho_{\mathrm{w}}=997 \mathrm{~kg} \cdot \mathrm{m}^{-3}, M_{\mathrm{w}}=0.018 \mathrm{~kg} \cdot \mathrm{mol}^{-1}\right.$ and $R=8.314 \mathrm{~J} \cdot \mathrm{K}^{-1} \cdot \mathrm{mol}^{-1}$ ) in Eq. (6), it follows:

$S=1+\frac{6.32 \times 10^{-7}}{T} \frac{1}{D_{\text {wet }}}-0.98 \frac{D_{\mathrm{me}_{0}}^{3}}{D_{\mathrm{wet}^{3}}^{3}-D_{\mathrm{me}_{0}}^{3}}$.

\section{Conclusions}

The hygroscopic growth of sea-salt particles generated from three different sea-water samples was investigated with LACIS at RHs from $80.0 \%$ up to $99.1 \%$. For comparison the growth of pure $\mathrm{NaCl}$ particles was considered, as well. The cubical shape of the $\mathrm{NaCl}$ particles was accounted for by using the shape factor of 1.08 . Additionally, electrical low pressure impactor measurements showed that sea-salt particles exhibit an aerodynamic behavior similar to that of $\mathrm{NaCl}$ particles. Consequently, the shape factor of 1.08 was used when converting from mobility to mass equivalent diameter.

The measurements showed that the hygroscopic growth of the three different sea-salt particles for the dry particle diameters of $139 \mathrm{~nm}$ and $185 \mathrm{~nm}$ agrees within the measurement uncertainties. The marginal differences in the chemical composition did not result in visible differences in the hygroscopic growth. The hygroscopicity of the three sea-water samples was always lower than that of the pure $\mathrm{NaCl}$ particles with the same dry sizes. This suggests that the existence of small amounts of additional less hygroscopic organic or insoluble material in the sea-salt particles reduces the hygroscopic growth slightly in comparison to pure $\mathrm{NaCl}$ particles.

The activation of the sea-salt particles was investigated for the supersaturations $0.11 \%, 0.17 \%$, and $0.32 \%$. The critical diameters $D_{\text {crit }}$ of the three sea-salt samples agree within the measurement uncertainties. As found in the hygroscopicity measurements, marginal differences in the chemical composition between the three sea-water samples caused no significant difference in the activation behavior. Additionally, the measured $D_{\text {crit }}$ of the sea-salt particles agree with those of pure $\mathrm{NaCl}$ within the measurement uncertainties for all supersaturations investigated.

For the first time, a CCN-closure was tested for sea-salt particles. For that purpose, hygroscopic growth data and simple Köhler theory were used to derive critical diameters which activated at the adjusted supersaturations for each sea-salt sample. For the closure, a mean value of $\rho_{\text {ion }}$ for each sample was determined based on measured hygroscopic growth at RHs between $95 \%$ and $99.1 \%$. With the derived values of $\rho_{\text {ion }}$, and assuming the surface tension of water, values of $D_{\text {crit }}$ were calculated. Measured and calculated values of $D_{\text {crit }}$ agreed within the uncertainties and consequently, $\mathrm{CCN}$-closure was performed successfully.

Based on the successful closure, a new parameterization to consistently describe sea-salt-particle hygroscopic growth (at $\mathrm{RH}>95 \%$ ) and activation has been developed.

\section{Appendix A}

It is well-known that dry $\mathrm{NaCl}$ particles possess a nonspherical shape. With the DMA selected mobility diameter $D_{\text {mob }}$ is not equal to the mass equivalent diameter $D_{\text {me }}$. Therefore $D_{\text {mob }}$ has to be shape corrected (Kelly and McMurry, 1992; Gysel et al., 2002).

Since the main component of the three different sea-salt samples is $\mathrm{NaCl}$, it is important to know if the generated sea-salt particles possess a shape factor, too. Additionally, it is also necessary to explore, if $\left(\mathrm{NH}_{4}\right)_{2} \mathrm{SO}_{4}$ particles need a shape correction, since these kind of particles are used for RH-calibration. For the detection, a system consisting of a DMA and an ELPI (Electrical Low Pressure Impactor, Fernández de la Mora et al., 1990) is used (see Fig. A1). The ELPI operates in the free-molecular regime, i.e., the mean free path of the molecules is significantly larger than the particle sizes. Therefore the retrieved particle diameter is the vacuum-aerodynamic diameter $D_{\text {va }}$.

For the investigations, the sea-salt particles were generated from the three different sea-water samples by using an atomizer. As reference $\mathrm{NaCl}$ and $\left(\mathrm{NH}_{4}\right)_{2} \mathrm{SO}_{4}$ particles were generated by atomizing an aqueous salt solution.

The resulting aerosol particles were dried in a diffusion dryer. A DMA was used to select several dry mobility diameters. One part of the selected quasi monodisperse aerosol was led into the CPC while the other was directed into the ELPI.

The impaction behavior is normally described by the Stokes-number Stk. For the ELPI Stk is written as (Fernández de la Mora et al., 1990):

$S t k=\frac{0.178 \dot{m} c_{0}^{3}}{8 h^{3}} \cdot \rho_{\mathrm{p}} D_{\mathrm{me}} \cdot \frac{1}{p^{2}}=\frac{l_{\text {stop }}}{h}$,

where $\dot{m}$ is the gas mass flow through the impactor nozzle, $c_{0}$ is the sonic speed, $2 h$ is the diameter of the impactor nozzle. Furthermore $\rho_{\mathrm{p}}$ and $D_{\mathrm{me}}$ are the bulk density and the 


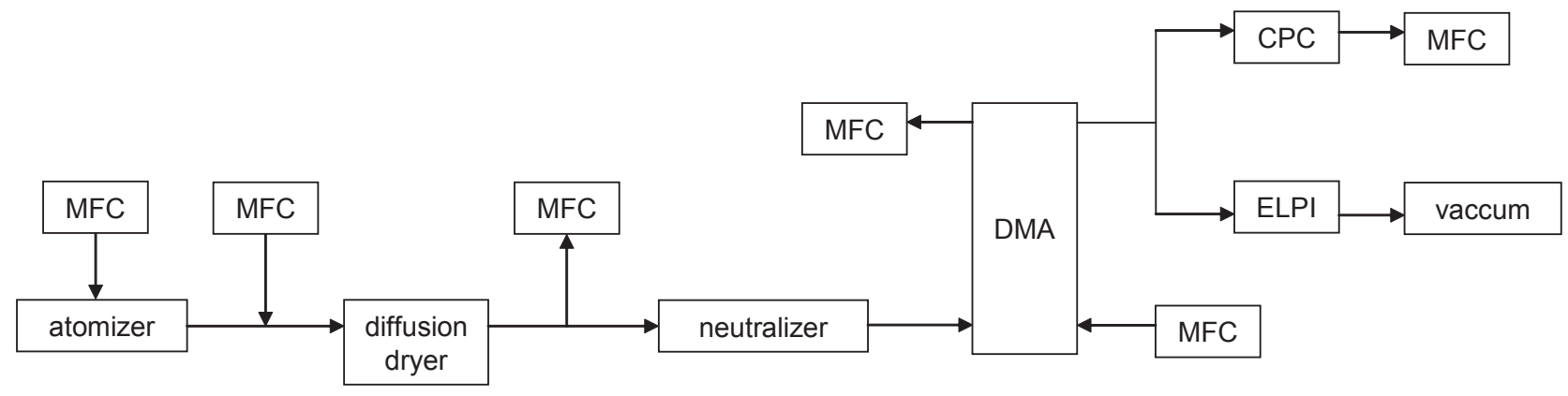

Fig. A1. Experimental setup for the calculation of the shape factor.

mass equivalent diameter of the particles and $p$ is the impact pressure in the ELPI chamber.

If the Stokes-number exceeds a critical value, the particles with one $D_{\text {va }}$ are deposited on the impactor plate. The pressure, where $50 \%$ of the particles with equal $D_{\text {va }}$ are deposited on the plate, is defined as the impaction pressure $p_{50}$. The connection between $D_{\text {va }}$ (respectively $D_{\text {me }}$ ) and $p_{50}$ is:

$\rho_{0} \cdot D_{\mathrm{va}}=\rho_{p} \cdot \frac{D_{\mathrm{me}}}{\chi_{v}}=k_{1} \cdot p_{50}^{2}+k_{2}$,

where $\chi_{v}$ is the shape factor of the free molecular regime and $k_{1}$ and $k_{2}$ are two constants which will be derived in the following. Replacing $D_{\text {me }}$ in Eq. (A2) through $D_{\mathrm{me}}=\frac{D_{\mathrm{mob}}}{\chi_{\mathrm{c}}} \frac{C_{\mathrm{c}}\left(D_{\mathrm{me}}\right)}{C_{\mathrm{c}}\left(D_{\mathrm{mob}}\right)}$ (see DeCarlo et al., 2004) yields:

$\rho_{p} \cdot D_{\mathrm{mob}}=\chi_{\nu} \chi_{\mathrm{c}} \frac{C_{\mathrm{c}}\left(D_{\mathrm{mob}}\right)}{C_{\mathrm{c}}\left(D_{\mathrm{me}}\right)}\left(k_{1} p_{50}^{2}+k_{2}\right)$,

where $\chi_{\mathrm{c}}$ is the shape factor in the continuum regime. $C_{\mathrm{c}}$ is the slip correction. The constants $k_{1}$ and $k_{2}$ were determined with Polystyrol-Latex (PSL) particles. For several $D_{\text {mob }}$ the corresponding impaction pressure $p_{50}$ values were determined. In Fig. A2, the product $\rho_{\mathrm{p}} D_{\text {mob }}$ is plotted against $p_{50}^{2}$ for the PSL particles. Since $\chi_{\mathrm{v}}=\chi_{\mathrm{c}}=1, D_{\mathrm{mob}}=D_{\mathrm{me}}$ and $\rho_{\mathrm{p}}$ is known for these particles, $k_{1}$ and $k_{2}$ can be determined from the slope and the location of the linear regression line.

For the $\mathrm{NaCl},\left(\mathrm{NH}_{4}\right)_{2} \mathrm{SO}_{4}$ and the sea-salt particles, the values of $p_{50}$ were determined for several $D_{\text {mob}}$, as well. For $\rho_{\mathrm{p}}$ of the different sea-salt samples, the values listed in Sect. 2 were used. In Fig. AA2, the product $\rho_{\mathrm{p}} D_{\text {mob }}$ is also plotted against $p_{50}^{2}$ for the $\mathrm{NaCl},\left(\mathrm{NH}_{4}\right)_{2} \mathrm{SO}_{4}$ and the sample I particles exemplarily. The data points of sample II and III are nearly identical to sample I. The collected data points were approximated by a linear regression.

It is obvious that the $\mathrm{NaCl}$ and sea-salt particles possess a similar aerodynamic behavior. So the product: $\chi_{\nu} \chi_{\mathrm{c}} \frac{C_{\mathrm{c}}\left(D_{\mathrm{mob}}\right)}{C_{\mathrm{c}}\left(D_{\mathrm{me}}\right)}$ is nearly identical for the $\mathrm{NaCl}$ and the sea-salt particles (the difference between the shape factors is about 0.003 , i.e. negligible). Therefore the shape factor of 1.08 was used for the sea-salt particles. The product $\chi_{\nu} \chi_{\mathrm{c}} \frac{C_{\mathrm{c}}\left(D_{\mathrm{mob}}\right)}{C_{\mathrm{c}}\left(D_{\mathrm{me}}\right)}$ for the

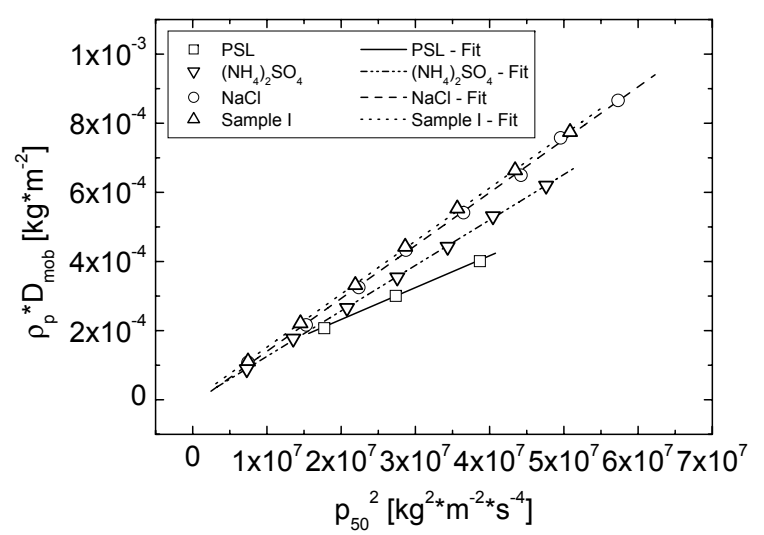

Fig. A2. The product $\rho_{\mathrm{p}} D_{\text {mob }}$ is plotted against $p_{50}^{2}$ for the PSL, $\mathrm{NaCl},\left(\mathrm{NH}_{4}\right)_{2} \mathrm{SO}_{4}$ and sea-salt (sample I) particles, to determine the shape factor of the $\left(\mathrm{NH}_{4}\right)_{2} \mathrm{SO}_{4}$ and the different sea-salt particles.

$\left(\mathrm{NH}_{4}\right)_{2} \mathrm{SO}_{4}$ particles lies in the middle between the product for PSL and $\mathrm{NaCl}$. Therefore for the calibration measurements a shape factor of 1.04 (as stated in literature: Biskos et al., 2006b; Zelenyuk et al., 2006) was considered for this kind of particles in the used size range.

\section{Appendix B}

The calibration of the relative humidity (saturation) inside of LACIS was performed with $\left(\mathrm{NH}_{4}\right)_{2} \mathrm{SO}_{4}$ particles with a dry $D_{\mathrm{mob}}=200 \mathrm{~nm}$. To investigate the influence of the particle shape on the RH calibration, the dry mobility diameter was corrected with shape factors of 1.00 and 1.04 . In Fig. BB1, RHs as determined from the hygroscopic growth of $\mathrm{NaCl}$ particles with a dry mass equivalent diameter $D_{\mathrm{me}_{0}}$ of $185 \mathrm{~nm}$ are plotted versus RHs resulting from the calibration with $\left(\mathrm{NH}_{4}\right)_{2} \mathrm{SO}_{4}$ particles assuming a shape factor of 1.00 (open squares) and a shape factor of 


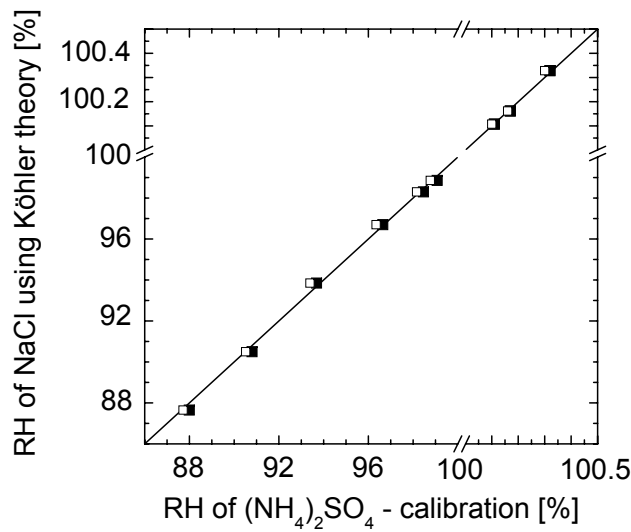

Fig. B1. RHs as determined from the hygroscopic growth of $\mathrm{NaCl}$ particles with $D_{\mathrm{me}_{0}}=185 \mathrm{~nm}$ are plotted versus RHs resulting from the calibration with ammonium sulfate particles $\left(D_{\mathrm{mob}}=200 \mathrm{~nm}\right)$ assuming a shape factor of 1.00 (open squares) and a shape factor of 1.04 (filled squares), respectively. Additionally, the $\mathrm{NaCl}$ data points, received from the activation measurements $(\mathrm{RH}>100 \%)$ are plotted.

1.04 (filled squares), respectively. Additionally, the three $\mathrm{NaCl}$ data points, retrieved from the activation measurements (RH $>100 \%)$ are plotted. For both materials Köhler theory according to Eq. (1) with the surface tension of water was used. For subsaturated conditions the difference in RH calibration using $\chi=1.00$ and $\chi=1.04$ ranges from $0.25 \%$ at $88 \%$ RH to $0.30 \%$ at $99 \%$ RH. For supersaturated conditions the difference amounts to $0.02 \%$. From earlier work regarding the sub- and supersaturations (and the corresponding uncertainties) inside LACIS we know about an uncertainty of approximately $\pm 0.30 \%$ at $99 \% \mathrm{RH}$ and $\pm 0.03 \%$ in the supersaturation range used in this study. Consequently, the influence of a shape factor of 1.04 vanishes within these uncertainties.

Edited by: D. Cziczo

\section{References}

Andreae, M. O. and Raemdonck, H.: Dimethyl sulfide in the surface ocean and the marine atmosphere: A global view, Science, 221, 744-747, 1983.

Andreae, M. O., Ferek, R. J., Bermond, F., Byrd, K. P., Engstrom, R. T., Hardin, S., Houmere, P. D., LeMarrec, F., Raemdonck, H., and Chatfield, R. B.: Dimethyl sulfide in the marine atmosphere, J. Geophy. Res., 90, D7, 12 891-12 900, 1985.

Biskos, G., Paulson, D., Russell, L. M., Buseck, P. R., and Martin, S. T.: Prompt deliquescence and efflorescence of aerosol nanoparticles, Atmos. Chem. Phys., 6, 4633-4642, 2006, http://www.atmos-chem-phys.net/6/4633/2006/.
Blanchard, D. C. and Cipriano, R. J.: Biological regulation of climate, Nature, 330, 526, 1987.

Blanchard, D. C. and Woodcock, A. H.: Bubble formation and modification in the sea and its meteorological significance, Tellus, 9, 145-158, 1957.

Blanchard, D. C. and Woodcock, A. H.: The production, concentration, and vertical distribution of the sea-salt aerosol, Ann. NY Acad. Sci., 338(1), 330-347, 1980.

Brüggemann, E. and Rolle, W.: Changes of some components of precipitation in East Germany after the unification, Water Air and Soil. Pollut. 107, 1-23, 1998.

Charlson, R. J., Lovelock, J. E., Andreae, M. O., and Warren, S. G.: Oceanic phytoplankton, atmospheric sulfur, cloud albedo and climate, Nature, 326, 655-661, 1987.

Cziczo, D. J., Nowak, J. B, Hu, J. H., and Abbatt, J. P. D.: Infrared spectroscopy of model tropospheric aerosols as a function of relative humidity: Observation of deliquescence and crystallization, J. Geophys. Res., 102, D15, 18 843-18 850, 1997.

Cziczo, D. J., and Abbatt, J. P. D.: Infrared observations of the response of $\mathrm{NaCl}, \mathrm{MgCl}_{2}, \mathrm{NH}_{4} \mathrm{HSO}_{2}$, and $\mathrm{NH}_{4} \mathrm{NO}_{3}$ aerosols to changes in relative humidity from 298 to 238 K, J. Phys. Chem., 104, 2038-2047, 2000.

DeCarlo, P. F., Slowik, J. G., Worsnop, D. R., Davidovits, P., and Jimenez, J. L.: Particle morphology and density characterization by combined mobility and aerodynamic measurements. Part 1 : Theory, Aerosol Sci. Technol., 38, 1185-1205, 2004.

Fernández de la Mora, J., Rao, N., and McMurry, P. H.: Inertial impaction of fine particles at moderate reynolds numbers and in the transonic regime with a thin-plate orifice nozzle, J. Aerosol Sci., 21, No. 7, 889-909, 1990.

Fitzgerald, J. W.: Marine aerosol: A review, Atmos. Environ., 25A, 533-545, 1991.

Gong, S. L., Barrie, L. A., and Blanchet, J.-P.: Modeling sea-salt aerosols in the atmosphere 1. Model development, J. Geophy. Res., 102, D3, 3805-3818, 1997.

Gysel, M., Weingartner, E., and Baltensperger, U.: Hygroscopicity of aerosol particles at low temperatures, 2 . Theoretical and experimental hygroskopic properties of laboratory generated aerosols, Environ. Sci. Technol., 36, 63-68, 2002.

Hudson, J. G. and Frisbie, P. R.: Cloud condensation nuclei near marine stratus, J. Geophy. Res., 96, D11, 20 795-20 808, 1991.

Kelly, W. P. and McMurry, P. H.: Measurement of particle density by inertial classification of differential mobility analyzergenerated monodisperse aerosols, Aerosol Sci. Technol., 17, 199-212, 1992.

Kiselev, A., Wex, H., Stratmann, F., Nadeev, A., and Karpushenko, D.: White-light optical particle spectrometer for in situ measurements of condensational growth of aerosol particles, Appl. Opt., 44, No. 22, 4693-4701, 2005.

Knutson, E. O. and Whitby, K. T.: Aerosol classification by electronic mobility: Apparatus, theory, and applications, J. Aerosol Sci., 6, 443-451, 1975.

Leck, C. and Bigg, E. K.: Source and evolution of the marine aerosol - A new perspective, Geophys. Res. Lett., 32, L19803, doi:10.1029/2005GL023651, 2005.

Leck, C. and Bigg, E. K.: Biogenic particles in the surface microlayer and overlaying atmosphere in the central Artic Ocean during summer, Tellus, 57B, 305-316, 2005.

O'Dowd, C. D. and Smith, M. H.: Physicochemical properties of 
aerosols over the northeast atlantic: Evidence for wind-speedrelated submicron sea-salt aerosol production, J. Geophy. Res., 98, D1, 1137-1149, 1993.

O’Dowd, C. D., Smith, M. H., Consterdine, I. E., and Lowe, J. A.: Marine aerosol, sea-salt, and the marine sulphur cycle: A short review, Atmos. Environ., 31, 73-80, 1997.

Pilinis, C., Pandis, S. N., and Seinfeld, J. H.: Sensitivity of direct climate forcing by atmospheric aerosols to aerosl size and composition, J. Geophy. Res., 100, D18, 18 739-18 754, 1995.

Pitzer, K. S., and Mayorga, G.: Thermodynamics of electrolytes, II. Activity and osmotic coefficients for strong electrolytes with one or both ions univalent, J. Phy. Chem., 77, No.19, 2300-2308, 1973.

Pruppacher, H. R. and Klett, J. D.: Microphysics of clouds and precipitation, Kluwer Academic Publishers, Dordrecht, The Netherlands, 1997.

Randall, D. A., Coakley, J. A., Fairall, C. W., Kropfli, R. A., and Lenschow, D. H.: Outlook for research on subtropical marine stratiform clouds, Bull. Am. Meteor. Soc., 65, 1290-1301, 1984.

Randles, C. A., Russell, L. M., and Ramaswamy, V.: Hygroscopic and optical properties of organic sea salt aerosol and consequences for climate forcing, Geophy. Res. Lett., 31, L16108, doi:10.1029/2004GL020628, 2004.

Seinfeld, J. H. and Pandis, S. N.: Atmospheric chemistry and physics: From air pollution to climate change, WileyInterscience Publication, Wiley, New York, 1998.
Stratmann, F., Kiselev, A., Wurzler, S., Wendisch, M., Heintzenberg, J., Charlson, R. J., Diehl, K., Wex, H., and Schmidt, S.: Laboratory studies and numerical simulations of cloud droplet formation under realistic supersaturation conditions, J. Atmos. Ocean. Technol., 21, 876-887, 2004.

Weis, D. D., and Ewing, G. E.: Water content and morphology of sodium chloride aerosol particles, J. Geophys. Res., 104, D17, $21275-21285,1999$.

Wex, H., Kiselev, A., Stratmann, F., Zoboki, J., and Brechtel, F.: Measured and modeled equilibrium sizes of $\mathrm{NaCl}$ and $\left(\mathrm{NH}_{4}\right)_{2} \mathrm{SO}_{2}$ at relative humidities up to $99.1 \%$, J. Geophy. Res., 110, D21212, doi:10.1029/JD005507, 2005.

Wex, H. and Kiselev, A. and Ziese, M., and Stratmann, F.: Calibration of LACIS as a CCN detector and its use in measuring activation and hygroscopic growth of atmospheric aerosl particles, Atmos. Chem. Phys., 6, 4519-4527, 2006, http://www.atmos-chem-phys.net/6/4519/2006/.

Wex, H., Hennig, T., Salma, I., Ocskay, R., Kiselev, A., Henning, S., Massling, A., Wiedensohler, A., and Stratmann, F.: Hygroscopic growth and measured and modeled critical super-saturations of an atmospheric HULIS sample, Geophy. Res. Lett., 34, L02818, doi:10.1029/2006GL028260, 2007.

Zelenyuk, A., Cai, Y., and Imre, D.: From agglomerates of spheres to irregularly shaped particles: Determination of dynamic shape factors from measurements of mobility and vaccum aerodynamic diameters, Aerosol Sci. Technol., 40, 197-217, 2006. 